\title{
Analysing risk and vulnerability of South African settlements: Attempts, explorations and reflections
}

\begin{tabular}{|c|c|}
\hline $\begin{array}{l}\text { Authors: } \\
\text { Elsona van Hu } \\
\text { Alize le Roux }{ }^{1} \\
\text { Willemien var }\end{array}$ & $\begin{array}{l}\text { yssteen }^{1} \\
\text { Niekerk }^{1}\end{array}$ \\
\hline \multicolumn{2}{|c|}{$\begin{array}{l}\text { Affiliations: } \\
{ }^{1} \text { Built Environment, Council } \\
\text { for Scientific and Industrial } \\
\text { Research (CSIR), South Africa }\end{array}$} \\
\hline \multicolumn{2}{|c|}{$\begin{array}{l}\text { Correspondence to: } \\
\text { Elsona van Huyssteen }\end{array}$} \\
\hline \multicolumn{2}{|c|}{$\begin{array}{l}\text { Email: } \\
\text { evhuyssteen@csir.co.za }\end{array}$} \\
\hline \multicolumn{2}{|c|}{$\begin{array}{l}\text { Postal address: } \\
\text { PO Box 395, Pretoria 0001, } \\
\text { South Africa }\end{array}$} \\
\hline \multicolumn{2}{|c|}{$\begin{array}{l}\text { Dates: } \\
\text { Received: } 10 \text { Aug. } 2012 \\
\text { Accepted: } 11 \text { Jan. } 2013 \\
\text { Published: } 19 \text { Feb. } 2013\end{array}$} \\
\hline \multicolumn{2}{|c|}{$\begin{array}{l}\text { How to cite this article: } \\
\text { Van Huyssteen, E., Le Roux, } \\
\text { A. \& Van Niekerk, W., } \\
2013 \text {, 'Analysing risk and } \\
\text { vulnerability of South African } \\
\text { settlements: Attempts, } \\
\text { explorations and reflections', } \\
\text { Jàmbá: Journal of Disaster } \\
\text { Risk Studies 5(2), Art. \#80, } \\
8 \text { pages. http://dx.doi.org/ } \\
10.4102 / j a m b a . v 5 i 2.80\end{array}$} \\
\hline \multicolumn{2}{|c|}{$\begin{array}{l}\text { Note: } \\
\text { 1st Biennial Conference, } \\
\text { Southern African Society for } \\
\text { Disaster Reduction (SASDiR), } \\
09 \text { to } 11 \text { October 2012, } \\
\text { Potchefstroom, South Africa }\end{array}$} \\
\hline \multicolumn{2}{|c|}{$\begin{array}{l}\text { Copyright: } \\
\text { (C) 2013. The Authors. } \\
\text { Licensee: AOSIS } \\
\text { OpenJournals. This work } \\
\text { is licensed under the } \\
\text { Creative Commons } \\
\text { Attribution License. }\end{array}$} \\
\hline \multicolumn{2}{|l|}{ Read online: } \\
\hline 口ifida & $\begin{array}{l}\text { Scan this QR } \\
\text { code with your } \\
\text { smart phone or } \\
\text { mobile device } \\
\text { to read online. }\end{array}$ \\
\hline
\end{tabular}

With the world's urban population now estimated to be at 52\% (United Nations 2012:1), towns and cities are increasingly becoming the stage where disaster risk has to be managed and mitigated. Understanding the risks and vulnerabilities in these complex socio-ecological systems thus becomes of utmost importance to be able to intervene in the underlying root causes, dynamic pressures and unsafe conditions. In this paper, the authors share their experience in, and reflect on, recent attempts at exploring integrated and place-specific risk and vulnerability analyses of settlements in South Africa. An overview is first provided of the attempt to develop multi-criteria indicators for integrated assessment of socio-economic vulnerability at a regional level. Secondly, an indication is provided of some first steps in interpreting projections for environmental risks and hazards in terms of possible implications for settlements at this regional level. The paper concludes with some reflections on the challenges and breakthroughs experienced in this exercise, as well as implications for on-going and future research.

\section{Introduction}

With a predicted urban population of $50 \%$ by 2020 for Asia and $50 \%$ by 2035 for Africa (United Nations 2012:1), trends in the developing world point to the critical role that towns and cities play in addressing such basic needs as access to food, water and safe shelter. In addition, towns and cities also play a significant role in household livelihoods through providing access to formal and informal networks, services, and employment opportunities. However, given that complex socio-environmental risks such as climate change, surface and groundwater availability, ecosystem vulnerability, land productivity, and food security all have an influence on the vulnerability and resilience of cities and towns, these spaces are also becoming the fulcrum for disaster risk reduction efforts (Pelling \& Wisner 2009).

The South African context is no exception. Towns and cities are presently estimated to be home to almost $68 \%$ of the national population, generating close to $85 \%$ of the country's economic activity and characterised by alarmingly high concentrations of poverty (see Van Huyssteen et al. 2009). The resilience of these spaces and the preparedness of urban areas to deal with disasters, risks and mounting vulnerabilities are therefore critical. However, even though it is well known that urban areas are increasingly vulnerable (Beall \& Fox 2009; Beall, Guha-Khasnobis \& Kanbur 2010; Pelling \& Wisner 2009), a huge need still exists for research and good practice that determine and explore ways to assess the vulnerability of settlements. This is especially so in a developing country where data and resources are scarce (Wisner et al. 2004; Adger et al. 2004; Birkmann 2011; Brooks, Adger \& Kelly 2005).

This paper contributes to the current discourse and body of research by providing an overview of, and reflection on, recent innovative attempts at exploring the vulnerability and risk exposure of settlements in South Africa in an integrated and place-specific way. The paper is based on an on-going series of analyses conducted by the authors (as part of the CSIR ${ }^{1}$ Spatial Planning and Systems group) for the 'socio-economic' and 'settlement' thematic areas of the South African Risk and Vulnerability Atlas (SARVA). Since 2009, the Risk and Vulnerability Atlas has been an initiative aimed at providing decision-makers with information on the impact and risk associated with global change in South Africa, and is spearheaded by the CSIR for the South African Department of Science and Technology (Archer, Engelbrecht \& Landman 2010).

This paper is structured in three parts, with the first part arguing the importance of responding to the increasing complexity of vulnerability and risk exposure in settlements, especially in the context of a developing country, such as South Africa. The second part provides an overview of some of the indicators and analyses developed for integrated assessment of socio-economic

1.The CSIR is the South African national research council for science and industrial research. 
vulnerability at a regional level, and an indication of some first steps in interpreting projections for environmental risks and hazards in terms of possible implications for settlements at this level. The third part reflects on challenges and lessons learned in the process of conducting risk and vulnerability analyses and on possible areas of future research.

\section{The vulnerability of (South African) settlements: Why it matters}

The vulnerability of settlements or communities may be described as the extent to which a settlement system is exposed and sensitive to negative implications of change, and the degree to which the subject community is able to anticipate, resist, cope with, adapt or recover ... The vulnerability of settlement systems thus includes not only susceptibility to physical changes but more importantly the impact such changes may have on social, economic and ecological subsystems and processes on which communities are dependant (DPCD 2008).

Vulnerability is caused by a complex combination of socioeconomic, physical, environmental and political root causes, dynamic pressure and unsafe conditions (Wisner et al. 2004). Political and economic ideologies affect the allocation and distribution of resources in a society, and are therefore the root causes of vulnerability. Dynamic pressures are the immediate manifestation of the underlying patterns and refer, among others, to population density and growth, unplanned urbanisation, inappropriate land use, environmental mismanagement, social injustice and poverty (UNISDR 2009; Wisner et al. 2004). For example, past apartheid planning is a root cause of vulnerability in South Africa, while the present patterns of urbanisation are dynamic processes that contribute to this vulnerability. Unsafe conditions are places people find themselves in, such as floodplains, hillsides, coastlines or in proximity to solid waste dumps.

Urban landscapes are extreme socio-ecological landscapes due to rapid urbanisation as well as the concentration of economic functions, social processes, ecosystems and physical infrastructure and buildings. They are increasingly becoming hotspots of disaster risk through the accumulation of poverty, lack of basic services, social unrest and conflict, and the extension of settlements into unsafe land. Urban space is also strategic and therefore tactical ground for terrorism and crime syndicates. The complexity of disaster risk is determined by the economic activities and livelihood strategies, resource availability, governance and public expectations, informality, and the potential for secondary impacts on the region. Furthermore, the larger that settlements grow, the more complex and compounded the disaster risk becomes (Collins 2009; Parnell, Simon \& Vogel 2007; Wamsler 2007).

South Africa shares many typical characteristics with other developing countries, but is also unique in some ways, e.g. the size of its economy, its history, the composition of its population, etc. South African settlements are generally complex and characterised by harsh socio-economic conditions. In addition to the typical challenges faced by a so-called 'developing' country, South Africa's socio-economic landscape is also characterised by significant inequalities, evident not only across income, age and racial groups but also starkly evident in space. Still reflecting the apartheid legacy, these spatial inequalities are influenced by a number of topographical and socio-economic factors and resultant historical and spatial path dependencies. Much urban growth in South Africa takes place outside strategic planning objectives, and infrastructure, service delivery and land use management do not reach many of these areas, therefore the institutional capacity to manage urban risk is severely constrained. Inappropriate planning and legislation may even exacerbate vulnerability in many cases (Biermann 2011; Oranje \& Van Huyssteen 2011; Todes 2011; Van Huyssteen et al. 2010). In considering the possible impacts of natural and human-made risks and hazards on socio-ecological systems, the vulnerability of such systems and the coping capacities of different regions and communities, it is imperative to understand the growth patterns and dynamics of population and economic activity across the South African landscape, as well as key temporal and spatial trends influencing them.

\section{South African settlement vulnerability and risk exposure analyses: An overview of explorations and attempts}

This section provides a brief introduction to SARVA and more specifically, the rationale and methodology of the human settlement and socio-economic components of the Atlas, using the latter components as a case study for exploring the vulnerability and risk exposure of settlements. As part of the case study, two examples are provided of developing integrated and context specific vulnerability profiles (see Figures 1 and 2). Building on these context-specific analyses, an example is also provided of how integrated but settlement-specific vulnerability can be combined with environmental disaster risk (in this specific case, projected extreme rainfall events - see Figure 3) to provide a more integrated understanding of risk and vulnerability.

\section{Brief introduction to the South African Risk and Vulnerability Atlas}

Given the South African context of limited information, the lack of capacity in many municipalities, especially in rural areas, as well as high costs for risk analyses, a need was identified to support decision makers to plan for resilient communities and address high levels of susceptibility. The SARVA platform is aimed at providing decision makers at local and regional scale '... with information on the impact and risk associated with global change in the region' (www.sarva.org.za). This is done through access to and visualisation of data dealing with the impacts of global change on human and natural environments through a number of themes, inter alia water, climate change, agriculture, and forestry. Funded by the South African Department of Science and Technology (DST), it is based on 


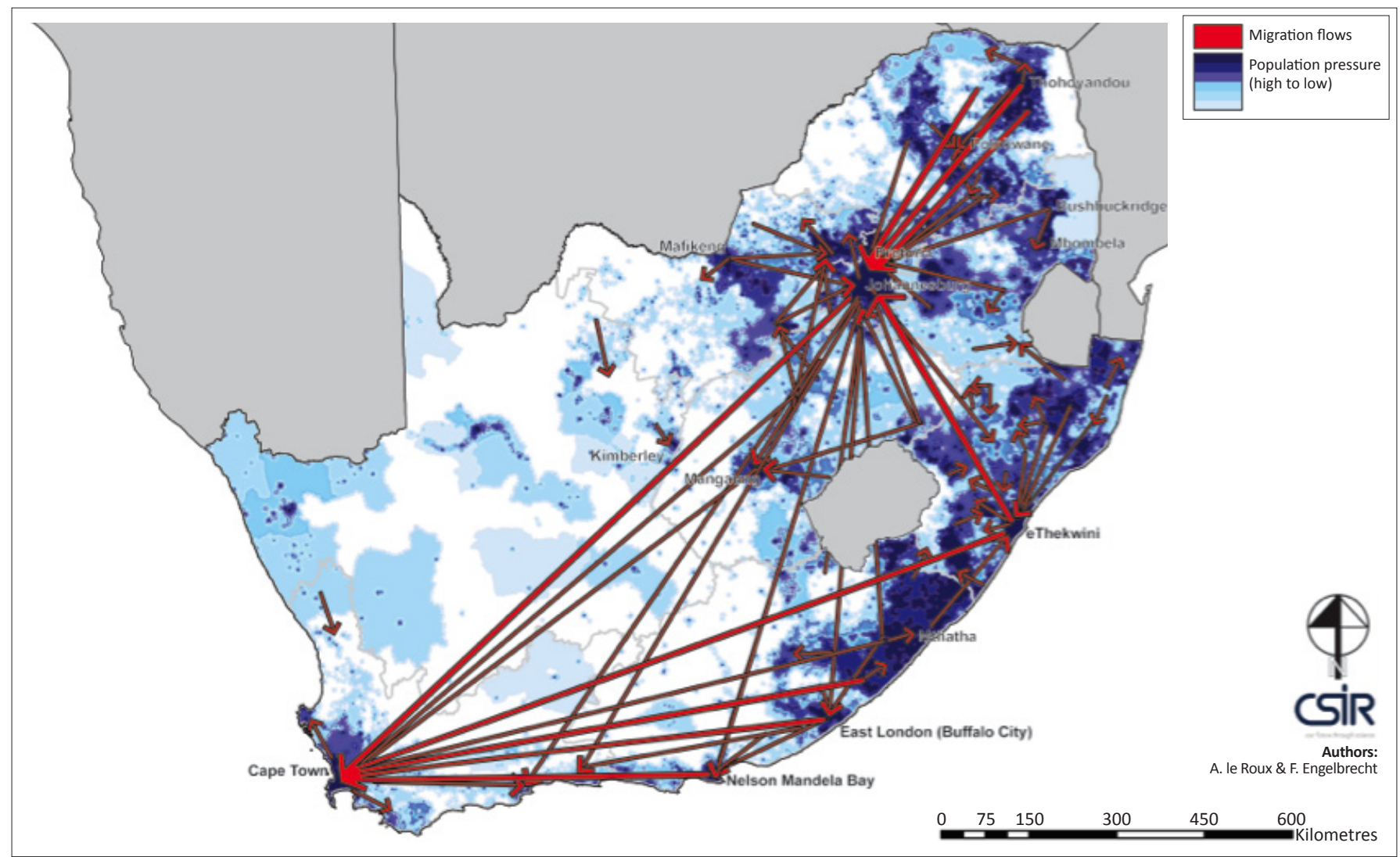

Source: CSIR mesoframe 2010 and StatsSA 2001, 2007; IPDM 2010 and IEC 2010 CSIR, Council for Scientific and Industrial Research.

FIGURE 1: South Africa's social pressure areas due to high population densities and population growth (the red arrows are an indication and/or proxy for the internal migration patterns and/or movement between 1999 and 2009).

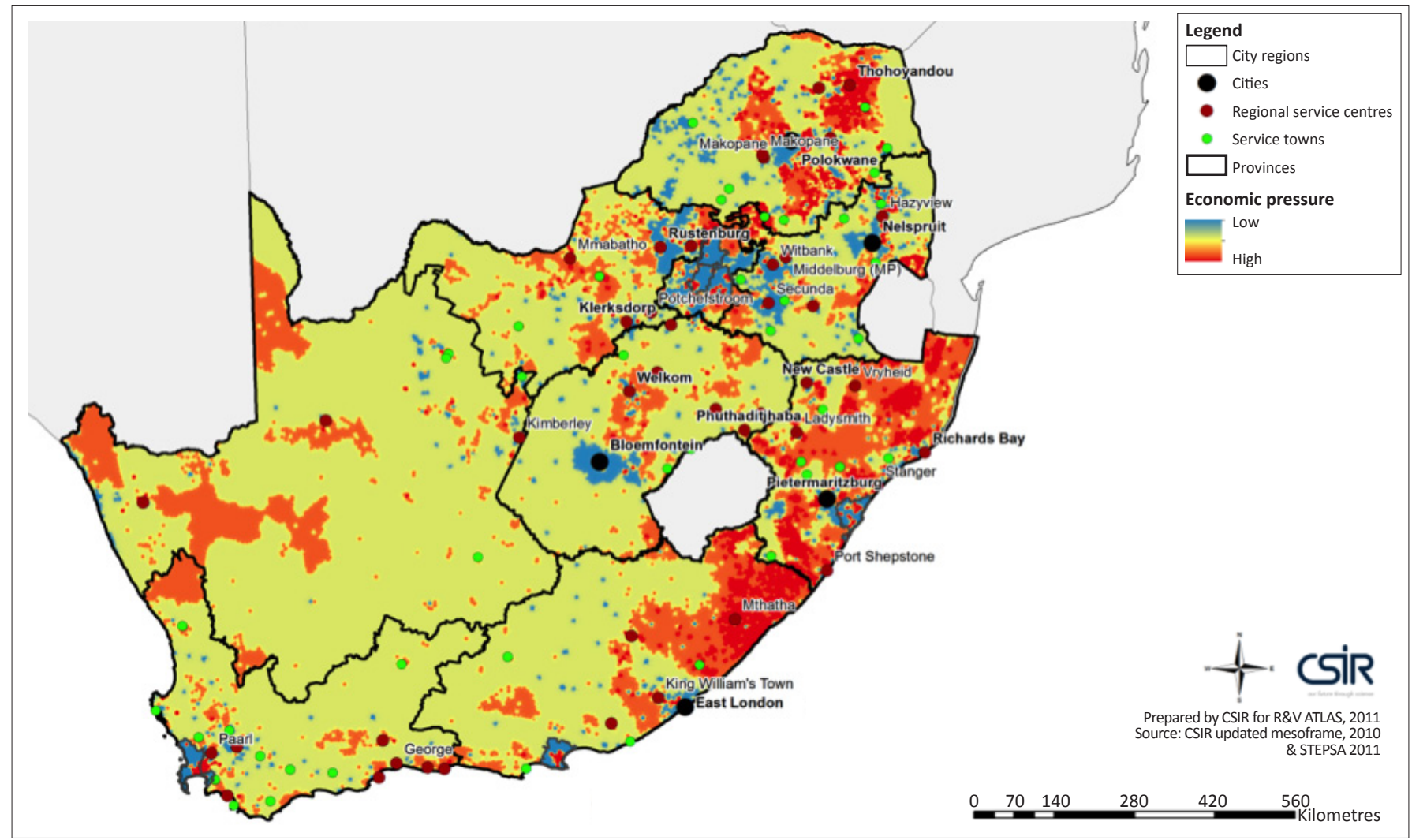

Source: Based on GDP per capita (CSIR GAP 2007), economic decline areas (Quantec 2010) and one sector economies (Quantec 2010) CSIR, Council for Scientific and Industrial Research.

FIGURE 2: South Africa's economic pressure areas. 


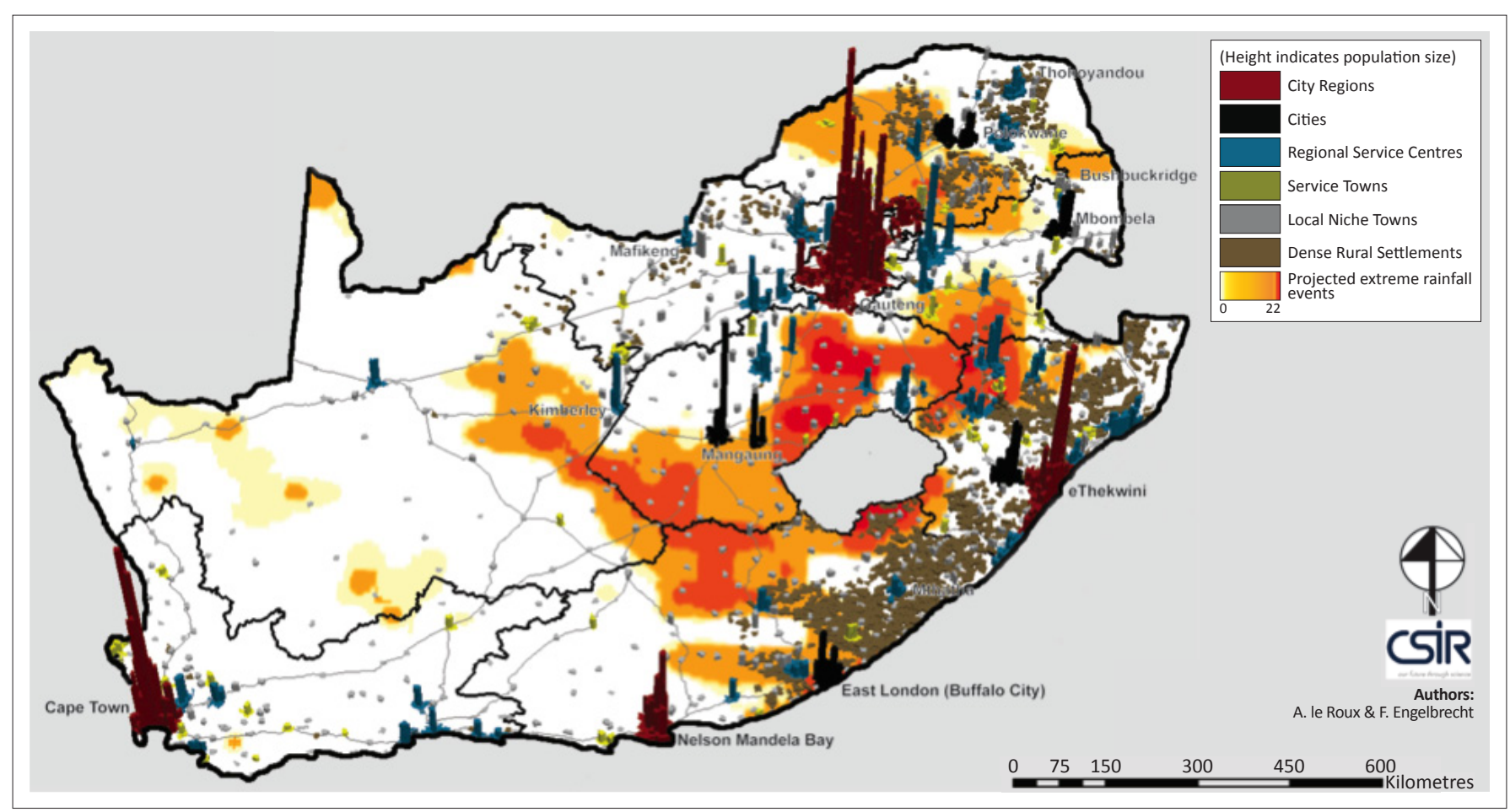

Source: CSIR mesoframe 2010, CSM and EH

CSIR, Council for Scientific and Industrial Research.

FIGURE 3: A map depicting the total population in 2007 (height of bar graphs) of various South African settlements (CSIR mesoframe 2010) and the projected change in the frequency of extreme rainfall events (CSM and EH). Such events are defined as $20 \mathrm{~mm}$ of rain or more that occurs within a $24-\mathrm{hour}$ period per $50 \mathrm{~km}^{2} \times 50 \mathrm{~km}^{2}$ grid box, for the near-future period, 2011-2040, relative to 1961-1990. Units of the rainfall variable are the number of rainfall events.

a shared platform that also hosts a number of key national environmental spatial databases, thus providing access to a large collection of scientific data and knowledge about South Africa. The socio-economic component, and even more so, the human settlement component (or 'themes' as defined in SARVA) have from the start been aimed at developing more integrated place and settlement-specific vulnerability indicators, and form the basis of the case study for this paper.

In its first phase, which started in 2009, this exploration of the vulnerabilities of South African settlements was aimed at developing indicators that enabled an integrated assessment of the socio-economic vulnerability and coping capacity of municipal areas. These indicators, it is argued, provide a valuable indication of longer-term risk that can lead to slow-onset disasters. The spatial analysis is based on local municipal datasets as well as on an innovative geospatial analysis platform (GAP) developed by the CSIR in 2006 and updated in 2010, which enables relational regional analyses across boundaries (in units known as mesozones). The geospatial platform (www.gap.csir.co.za) provides detailed information on the geographical distribution of population and economic activity across the country. Through advanced spatial analyses, these information sets (e.g. population growth patterns, migration trends, population densities) are used to quantify South Africa's socio-economic patterns, pressures and multi-stressor areas.

In its second phase, the exploration is currently aimed at exploring the potential impacts of natural hazards on settlements and regions within their specific geographical and socio-economic contexts. These include a range of environmental hazards (often climate change related) such as sea level rise, groundwater vulnerability and extreme rainfall events, mostly as identified within the range of other themes or focus areas within SARVA.

All the above information and sets of analyses are being made available through the SARVA portal (www.sarva.org.za), a hard copy atlas, a series of newsletters, as well as a structured series of seminars and capacity building workshops throughout the country. The latter are specifically aimed at raising awareness about risk and vulnerability, identifying key gaps and priority research areas, and encouraging use of the SARVA amongst municipalities in the country.

\section{Socio-economic vulnerability and regional profiles}

As a first step, a series of regional profiles was developed to identify critical social and economic vulnerabilities, aimed specifically at providing analyses and information that could support municipal integrated planning, disaster risk management and spatial planning processes in resource and data scarce environments. This exploration resulted in the development of indicators of the socio-economic vulnerability of municipal areas, identifying critical risks building up through, for example, increasing poverty, unemployment, population growth and in-migration. Risk implications are obviously higher in areas characterised by high and increasing development pressures on the natural 
environment, as well as in areas characterised by high socio-economic vulnerability. In such a way, areas with high socio-economic vulnerability and areas of high risk (also because of concentration of national assets or even strategic infrastructure) can be identified in order to prioritise and support integrated development, disaster risk management, as well as adaptation strategies.

Indications of formal economic activities and growth, economic dependencies and employment play a key role in understanding levels of access to livelihoods and services, and, together with the wide range of informal economic activities, these strongly influence coping capacities and resilience. Understanding these dynamic patterns and how they change and play out in space can help to better identify national and regional economic assets as well as economic risk-prone and dependent areas.

In order to develop the regional profiles and comparative analyses of the socio-economic vulnerability and coping capacity of an area or municipality, a range of basic analyses was initially conducted, which included the following:

- Determining trends in population distribution and population growth - providing an indication of areas under pressure due to high population densities, high natural growth rates, as well as high levels of in-migration.

- Determining trends in the geographic distribution of economic and employment growth and decline - providing an indication of areas that are supporting significant national and regional socio-economic assets, as well as areas under pressure due to high levels of unemployment and dependency.

- Identification of areas with high resilience (but also facing high risks) because of significant national and regional socio-economic assets.

- Relative resilience of areas illustrated by levels of economic growth and decline and the geographic distribution thereof for various economic sectors.

- Identification of areas with high levels of social vulnerability due to high levels of unemployment and dependency, as well as continued employment and economic decline, with resultant increased dependency on the employed and a lower quality of life.

After various explorations, however, it was clear that a few key indicators combined in one composite index seem to provide quite robust composite profiles of the critical social and population pressures and the socio-economic vulnerabilities. Two of these indicators are:

- Critical social and population related pressures - an indication of areas and local municipalities with high levels of socio-economic vulnerability due to high levels of population density, natural growth and in-migration (see Figure 1).

- Critical socio-economic vulnerabilities - an indication of areas and local municipalities with high levels of socioeconomic vulnerability due to low levels of economic activity and high dependency rates (see Figure 2).

\section{Social and population related pressure areas}

Areas that are socially vulnerable are typically communities with high disparities in income, high levels of poverty, high illiteracy rates, age dependencies, political instability, high population concentrations, ethnic minorities, single-headed households, population growth, migration and limited access to livelihoods and services backlogs.

A first round, composite index has taken into account three of the above factors (population density, growth and migration) and is a good start at pinpointing South Africa's social vulnerable areas. Figure 1 indicates the highest population pressure areas based on natural population growth between 2001 and 2007 (StatsSA 2007 data) and population densities per mesozone (CSIR GAP 2010 data). These areas are typically more vulnerable to hazards due to high population densities and continued pressure as a result of natural growth and in-migration. Most of the population pressure areas (dark blue) are also places that are characterised by increased poverty, inequalities, violent crime, lack of employment, backlogs, and service delivery protests.

At a broad regional level, the areas under the biggest pressure seem to be:

- The extended Gauteng City region and the network of towns around the corridors extending from it.

- The former homeland areas and densely settled rural areas in the northern and eastern parts of the country, and especially the secondary cities and major regional centres and/ or towns in those areas.

- The Cape Town metropolitan area and southern Cape coastal regions and tourist towns.

- The eThekwini metropolitan area and surrounds, the densely settled eastern coastal and inland areas, with higher densities in the more economically viable coastal towns to the south and the north, as well as along the Gauteng-eThekwini corridor.

- Concentrated areas around key service towns in the more sparsely populated north-western and central parts of the country.

\section{Economic pressure areas}

Economic pressure areas are usually characterised by high levels of poverty, where large parts of the population are dependent on state grants, where economies are dependent on single sectors, and are marked by declining economies, services backlogs, high unemployment, low GDP per capita and high income inequalities.

A first round, multi-criteria analysis has taken into account three of the above factors (GDP per capita, diversity of the economy and economic decline). Given the spatial trends of other indicators, these selected indicators have been shown to provide a rather robust pattern reflecting the economic activity and trends of the respective regions. 
Figure 2 indicates a regional overview of the economic pressure areas (red areas on map) based on a low GDP per capita, economies dependent on one economic sector and areas where the economy declined between 2001 and 2007. As could be expected, at a broad regional level, the areas under the biggest pressure are:

- The densely settled former homelands along the eastern coast and in the northern parts of the country.

- Areas surrounding the metropolitan areas and major towns - illustrating settlement-specific dynamics (especially if more zoomed-in views are created).

- Towns in resource-dependent areas and former mining towns, often marked by high unemployment levels in spite of some economic activity.

- Secondary cities and surrounding areas in the central and northern parts of the country, marked by a declining industrial sector and high unemployment.

- Coastal towns along the southern and eastern coastlines, characterised by high in-migration and unemployment.

\section{Integrated settlement vulnerability and risk profiles}

Based on the geo-spatial analyses platform (CSIR 2010), and through a broader national initiative conducted for the South African Cities Network, the Presidency and former Department of Provincial and Local Government (SACN et al.. 2009) a settlement typology was developed for South Africa, identifying and demarcating a range of cities and towns. Almost $68 \%$ of the national population are settled within this range of cities and towns, in which $34 \%$ of people are located in the major metropolitan areas, 20\% in secondary cities and big towns, and a further $13 \%$ within smaller service towns (CSIR 2011). The resilience of these spaces and their preparedness to deal with disasters, risks and increasing vulnerabilities are increasingly important. Whilst metropolitan areas and secondary cities are largely dealing with socio-economic pressures and major issues around future water availability, smaller towns are subject to issues such as groundwater availability and temperature increases affecting surrounding agriculture areas.

As a second step in the current phase of the SARVA, the exploration is focussed on collaboration between various disciplines and sectors in order to combine socio-economic and bio-physical analyses conducted through the respective SARVA components to identify a range of possible risks and impacts posed by natural hazards to specific settlements. An example of one of the integrated analyses conducted thus far is the relation between settlement location and projected extreme rainfall events.

\section{Settlement vulnerability to projected extreme rainfall events}

In order to better understand and determine the possible socio-economic impact of climate change on settlements, projected extreme rainfall events have been related to settlement and socio-economic profiles. It is evident from the analyses that dense settlements housing high levels of human capital and social and economic infrastructure are often also characterised by high levels of socio-economic pressure. ${ }^{2}$ Figure 3 indicates areas of high risk in terms of the vulnerability of social and human-made resources and infrastructure combined with high natural risks - more specifically, projected extreme rainfall events associated with projected global climate change.

From the analyses it can be estimated that 5.8 million South Africans could be affected by extreme rainfall events. The biggest impacts by far are on already vulnerable communities within dense rural settlements (identified areas house almost 1.9 million people); local and niche towns in the affected areas (housing more than 1.6 million people); as well as service towns (housing almost 1.6 million people in the identified areas). These settlements and towns also largely fall within municipalities with poor capacity and few resources.

\section{Exploring the vulnerability of settlements: Reflections, challenges and lessons learned}

The above analyses identified those areas in South Africa that are under the biggest social and economic pressures. The third map combines this with the projection of extreme rainfall events, to give a combined risk and vulnerability analysis. Indicators and information in this regard published in the Risk and Vulnerability Atlas will support researchers and decision makers to anticipate and mitigate risks in vulnerable settlements. This will allow a start to be made in answering pertinent questions about the country's economic assets and socio-economically distressed areas.

However, in contributing towards the broader discourse on settlement and place-specific risk and vulnerability analyses, what might be even more useful than sharing findings from the analyses themselves are the lessons learned through these attempts and explorations. Reflecting on the process and methodologies developed and utilised in compiling these risk and vulnerability profiles, a number of key challenges and lessons can be highlighted.

\section{Moving beyond mere definitions}

It is generally very important to clarify terminology throughout a process. However, it is more important to understand the underlying processes that contribute to risk and vulnerability and how to intervene in those processes than to get stuck in an attempt at differentiating 'risk' and 'vulnerability', especially given that 1 ) South African settlements are at risk of compound, everyday risks (complexity) rather than major events and that 2) many people involved in planning resilient cities are not experts in either disaster reduction or resilience (capacity). In practice, the difference is fuzzier - risk is often vulnerability under different circumstances.

2.The risk profile was created through the SARVA initiative in collaboration by the CSIR Built Environment (SA town and settlement typology working group) and CSIR Natura Resource and Environment (climate change working group). 
Pelling (2011) also agrees with this point by stating that it is more important to understand the underlying processes that lead to vulnerability than to separate the categories of risks. In other words, there is a correlation between the problems of the distribution of risks and the problems and conflicts relating to the distribution of scarce resources. To relieve the pressure of risk, vulnerability has to be reduced. An integrative approach towards reducing risks and vulnerabilities is therefore more important than attempting to mitigate a single type of hazard.

\section{Contributing in a resource and data scarce environment}

In a country such as South Africa that does not have sufficient funds or capacity to do a risk and vulnerability analysis for every potential risk and vulnerability from a national to local scale, it is important to rather identify those proxies that reflect numerous socio-economic vulnerabilities, for many of the spatial characteristics overlap to a great extent (e.g. poverty and social grants will have a strong correlation). It is important to have a clear indication of the overall risk and vulnerability of places that can be made available and is easily accessible to municipal and other role players and decision makers.

\section{Enabling integrated interventions}

If one concentrates on individual analysis of risks and vulnerabilities, one is at risk of thinking about interventions in the same way. However, composite analyses allow for more strategic interventions in building resilient cities that start to address a number of underlying processes. Strategic interventions based on composite analyses become more pro-active and less reactive in mitigating the risks.

\section{Utilising technology and capacitating practitioners to engage}

There have been great scientific advances in the field of geoscience and the application of spatial analyses tools and platforms. More and better data are available and easier integration and access becomes possible - all aspects contributing to more evidence-based planning. The data are very useful for spatial development frameworks, integrated development plans, disaster risk management, municipal reporting, etc. The integration of the data with these plans is crucial; however, this will only happen when practitioners are sensitised about the issues, data availability and value of the tools. Awareness-raising and capacity-building initiatives, during which practitioners start using and integrating the data themselves, and more so, start to question implications, have proven to be quite successful.

\section{The costs and benefits of interdisciplinary research collaboration}

The benefits from interdisciplinary research collaboration are certainly worth the investment in time and costs. However, the time and costs should not be underestimated. The SARVA is currently in its third year, and interdisciplinary collaboration is only really starting to take shape. It has taken this long for the development of mutual learning, understanding each other's languages, creating trust, getting the data to talk to each other, and understanding what the mutual questions are.

\section{Future research focus}

The future research focus of the Risk and Vulnerability Atlas will be on compiling more integrated risk and vulnerability profiles in collaboration with various disciplines and sectors in order to combine socio-economic and bio-physical analyses such as impacts of projected climate change, water stress and scarcity, and biodiversity - some of the major needs identified by local practitioners.

\section{Conclusion}

Settlements in developing countries such as South Africa not only play an increasingly important role in providing households with access to basic services, housing and livelihoods, but also as key actors in regional economies. In this paper, the authors argued that given the complexities, the increased pressures and risks associated with socioeconomic vulnerabilities and global change factors, as well as the resource and data scarce contexts prevailing in the developing world, it seems worthwhile and possible to:

- Consider the development of integrated place-specific indicators of risk and vulnerability to support decision making.

- Utilise these socio-economic vulnerability analyses to determine possible implications of projected environmental risks for settlements.

In reflecting on the challenges and breakthroughs experienced in this exercise, it is evident that such analyses can add a lot of value given current capacities, especially in the local government environment. Clearly, there is scope for much more inter-disciplinary research and collaboration nationally, and a need to compare experiences and lessons with that of other similar exercises and attempts internationally, and especially in the southern African context.

\section{Acknowledgments Competing interests}

The authors are actively involved in the development of the South African Risk and Vulnerability Atlas and the paper serves as a reflection on this experience.

\section{Authors' contributions}

A.L.R. (CSIR) and E.V.H. (CSIR) have been involved in the South African Risk and Vulnerability Atlas since 2009 and are responsible for the socio-economic and settlement analyses. W.V.N. (CSIR) joined this initiative in 2012 and is conducting her PhD studies in the field of urban resilience and disaster reduction at the African Centre for Disaster Studies, North West University. She made conceptual contributions. Credit should also be given to Emma Archer van Garderen, 
Julia Mambo and Kristy Faccer (all from Natural Resource and Environment, CSIR) as respective project leaders of the South African Risk and Vulnerability Atlas (RAVA), as well as to the respective theme conveners within this project.

\section{References}

Adger, W., Brooks, N., Bentham, G., Agnew, A. \& Eriksen, S., 2004, New indicators of vulnerability and adaptive capacity, Tyndall Centre for Climate Change Research, Norwich.

Archer, E., Engelbrecht, F., Landman, W. et al., 2010, South African risk and vulnerability atlas, CSIR and DST, Pretoria.

Beall, J. \& Fox, S., 2009, Cities and development, Routledge, Oxford.

Beall, J., Guha-Khasnobis, B. \& Kanbur, R., 2010, 'Introduction: African development in an urban world: Beyond the tipping point', Urban Forum 21, 187-204.

Biermann, S., 2011, 'Planning support systems in a multi-dualistic spatial planning context', Journal of Urban Technology 18(4), 5-37. http://dx.doi.org/10.1080/106 30732.2011.648432

Birkmann, J., 2011, 'Risk and vulnerability indicators at different scales: Applicability, usefulness and policy implications', Environmental Hazards 7(1), 20-31. http:// dx.doi.org/10.1016/j.envhaz.2007.04.002

Brooks, N., Adger, W. \& Kelly, P., 2005, 'The determinants of vulnerability and adaptive capacity at the national level and the implications for adaptation', Global Environmental Change 15, 151-163. http://dx.doi.org/10.1016/j.gloenvcha.2004.12.006

Collins, A., 2009, Disaster and development, Routledge, Oxford.

CSIR, 2010, 'Geospatial analysis platform (GAP)', viewed April 2012, from http://www. gap.csir.co.za.

CSIR, 2011, Resource document for the National Planning Commission: Section 6 - A brief overview of the South African settlement and land development, Unpublished report prepared by the CSIR for the National Planning Commission Material Conditions Working Group's Diagnostic Report, viewed April 2012, from http://www.stepsa.org.za.
DPCD (Department of Planning and Community Development), 2008, 'Settlement vulnerability assessment: Methods, measures and current scope of measuring
the vulnerability of Victorian communities', State Government of Victoria, DPCD, viewed July 2008, from http://www.dpcd.vic.gov.au/_data/assets/pdf_file/ 0017/ viewed July 2008, from http://www.dpcd.vic.gov.au/

Oranje, M. \& Van Huyssteen, E., 2011, 'Nestling national "transformation” imperatives in local "servicing" space: Critical reflections on an intergovernmental planning and implementation project', Town and Regional Planning 58, 6-16.

Parnell, S., Simon, D. \& Vogel, C., 2007, 'Global environmental change: conceptualising the growing challenge for cities in poor countries', Area 39(2), 357-369. http:// dx.doi.org/10.1111/j.1475-4762.2007.00760.x

Pelling, M., 2011, Adaptation to climate change: From resilience to transformation, Routledge, Oxford.

Pelling, M. \& Wisner, B., 2009, Disaster risk reduction: Cases from urban Africa, Earthscan, London.

South African Cities Network (SACN), DPLG and the Presidency, 2009, National spatial trends overview, unpublished report.

Todes, A., 2011, 'Reinventing planning: Critical reflections', Urban Forum 22, 115-133.

UNISDR, 2009, 'Terminology on disaster risk reduction', UNISDR (United Nations International Strategy for Disaster Reduction), viewed 19 August 2010, from http://www.unisdr.org/eng/terminology/terminology-2009-eng.html.

United Nations, 2012, World urbanization prospects: The 2011 revision, Department of Economic and Social Affairs, United Nations, New York.

Van Huyssteen, E., Oranje, M.C., Robinson, S. \& Makoni, E., 2009, 'South Africa's city regions: A call for contemplation ... and action', Urban Forum 20, 175-195.

Van Huyssteen, E., Meiklejohn, C., Coetzee, M., Goss, H. \& Oranje, M., 2010, 'An overview of South Africa's metropolitan areas - dualistic, dynamic and under threat ...' European Spatial Research and Policy 17(2), 23-40. http://dx.doi. org/10.2478/s10105-010-0008-2

Wamsler, C., 2007, 'Managing urban disaster risk: Analysis and adaptation frameworks for integrated settlement development programming for the poor', PhD thesis in Housing Development and Management, Department of Architecture and Building Environment, Lund University.

Wisner, B., Blaikie, P., Cannon, T. \& Davis, I., 2004, At risk: Natural hazards, people's vulnerability and disasters, 2nd edn., Routledge, Oxford. 